\title{
A PROPOSTA DE TRABALHAR A TEMÁTICA EDUCAÇÃO AMBIENTAL NO ÂMBITO ESCOLAR DE FORMA INTERDISCIPLINAR INSERIDO NO PROJETO POLÍTICO PEDAGÓGICO
}

\author{
Leonardo Dias Ariane Silva ${ }^{1}$ \\ Robson Luiz Calmon Costa²
}

\section{Resumo}

Esta pesquisa aborda a temática Educação Ambiental no âmbito escolar, como uma proposta inserida no Projeto Político Pedagógico tomando como perspectiva uma visão crítica realizando reflexões, de que a educação ambiental desenvolvida de forma interdisciplinar contribuiu como uma ferramenta de suporte no desenvolvimento da cidadania e na conscientização do uso dos recursos naturais de maneira sustentável. A Educação Ambiental é a preparação do indivíduo, mediante a compreensão dos principais problemas do mundo contemporâneo, proporcionando-lhe conhecimentos e habilidades necessárias para desempenhar uma função produtiva, com vistas a melhorar a vida e proteger o meio ambiente, articulando valores éticos em função da qualidade de vida. A metodologia utilizada foi a, pesquisa bibliográfica em livros, artigos e revistas que abordam a temática interdisciplinaridade e Educação Ambiental. Conclui-se que um projeto de Educação Ambiental (EA) interdisciplinar nas escolas contribui para promover a consciência ambiental nos alunos adotando assim atitudes e hábitos que busquem a sustentabilidade ambiental.

Palavras Chave: Educação Ambiental. Interdisciplinaridade. Cidadania

\begin{abstract}
This research addresses the issue of Environmental Education in the school environment, as a proposal inserted in the Political Pedagogical Project taking as a perspective a critical view making reflections, that the environmental education developed in an interdisciplinary way contributed as a support tool in the development of citizenship and awareness the use of natural resources in a sustainable manner. Environmental Education is the preparation of the individual, by understanding the main problems of the contemporary world, providing him with the knowledge and skills necessary to perform a productive function, with a view to improving life and protecting the environment, articulating ethical values according to the quality of life. The methodology used was bibliographic research in books, articles and magazines that address the interdisciplinary and Environmental Education theme. It is concluded that an interdisciplinary Environmental Education (EA) project in schools contributes to promote environmental awareness in students, thus adopting attitudes and habits that seek environmental sustainability.
\end{abstract}

Keywords: Environmental Education. Interdisciplinarity. Citizenship

\footnotetext{
${ }^{1}$ Mestre em Ciências da Educação pela Facultad Interamericana de Ciencias Sociales (FICS). Especialista em Educação Ambiental pela Universidade Federal da Bahia (UFBA) e Educação de Jovens e Adultos (EJA) pela Faculdade Venda Nova do Imigrante (FAVENI). Gestor da Prefeitura Municipal de Salvador, professor da Secretaria da Educação do Estado da Bahia e tutor pela UNEFEaD. E-mail: leonardo.ariane@gmail.com

2 Mestre em Ciências da Educação pela Facultad Interamericana de Ciencias Sociales (FICS). Especialista em Gestão Ambiental pela Universidade Gama Filho. Especialista em Metodologia de Ensino na Educação Superior Faculdade Visconde de Cairu. Docente de Ciências Naturais e Biologia da Secretaria de Educação do Estado da Bahia. Docente de Ciências Naturais da Prefeitura Municipal de Salvador. Email: nosborcalcost@hotmail.com.br/nosborcalcost@gmail.com
} 


\section{Introdução}

A questão ambiental tem se tornado um tema frequente nos meios midiáticos, acadêmicos e políticos, como uma problemática existente entre a sociedade moderna - capitalista e industrial - e suas relações com a natureza, sobretudo, diante de fatores como urbanização, aumento populacional, limites dos recursos naturais, poluição dos rios, desmatamento, mudanças climáticas, entre outros. A tradicional visão naturalista que tende a interpretar o meio ambiente apenas do ponto de vista ecológico durante anos disseminou vertentes conservadoras de proteção ambiental de modo radical e restrito (CARVALHO, 2006).

O entendimento moderno que o homem faz parte do meio ambiente - por relação direta de dependência - e que os problemas ambientais não se restringem aos fatores ecológicos, pois são produtos também dos fatores sociais, históricos, políticos, culturais e econômicos, deslocou a perspectiva ambiental dessa visão científica conservadora e focou discussão na necessidade de harmonizar as interações sociais e as dinâmicas da natureza (lbid.).

A Educação Ambiental tornou-se uma ferramenta para confrontação desses problemas, uma vez que através dela o homem pode deter conhecimentos necessários ao equilíbrio ecológico. Tal entendimento despertou a necessidade global em construir uma nova ética planetária, que promova mudanças de comportamento e consciência ecológica crítica para fortalecer visões sobre meio ambiente, sociedade e desenvolvimento (REBOUÇAS, 2012).

A escola tornou-se um ambiente propício para que o indivíduo venha discutir de forma críticas os problemas enfrentados pelo meio ambiente e busquem soluções praticas para os problemas ambientais identificados pela comunidade escolar. Porém a forma de como a escola veem trabalhando a educação ambiental na maioria das vezes são ineficazes,.

Através de um Projeto Interdisciplinar sobre Educação Ambiental o indivíduo irá desenvolver competências e habilidades que irá lhe proporcionar a aquisição de conhecimento e mudanças de atitudes voltadas para a conservação ambiental e a sustentabilidade. De acordo com as Diretrizes Curriculares Nacionais para a Educação Ambiental $^{3}$ (DCNEA), apresenta em seu artigo $2^{\circ}$ a seguinte concepção:

\footnotetext{
${ }^{3}$ São orientações para a Educação Básica dos sistemas de ensino para a organização, articulação e desenvolvimento das propostas pedagógicas nacionais voltadas para questões ambientais.
} 
A Educação Ambiental é uma dimensão da educação, é atividade intencional da prática social, que deve imprimir ao desenvolvimento individual um caráter social em sua relação com a natureza e com os outros seres humanos, visando potencializar essa atividade humana com a finalidade de torná-la plena de prática social e de ética ambiental (BRASIL, 2012, p. 206-207).

Com base em tais Diretrizes, as práticas pedagógicas fazendo uso de conteúdos, projetos ou atividades ambientais estão respaldadas pela lei 9.795/99 que institui a Política Nacional de Educação Ambiental ${ }^{4}$ (PNEA), apresentando um caráter interdisciplinar, através de uma abordagem integrada e contínua, não podendo ser implantada como uma nova disciplina no currículo de ensino.Nesse complexo cenário, de crise ambiental contemporânea e a necessidade de desenvolver a consciência ecologia é que a Educação Ambiental se tornou mecanismo fundamental para promover a troca de experiências e informações que busquem harmonizar as relações entre sociedade e natureza.

\section{Educação Ambiental na Escola}

No entanto, no contexto escolar, a persiste a concepção arcaica que percebe a questão ambiental sob o olhar do ensino de ecologia, percebendo uma tendência da efetivação de ações voltadas a Educação Ambiental apenas na transmissão de conhecimentos, que se preocupam com a preservação do verde, das florestas e dos animais, sem desenvolver o sentimento de interação do aluno com o meio, que foram práticas que representaram os projetos educacionais voltados a EA no âmbito escolar.

Tais ações proporcionavam uma visão limitada da realidade, possibilitando a incorporação da Educação Ambiental apenas como instrumento que viesse atender aos caprichos do mundo capitalista e ao perfil consumista da sociedade moderna, sem a mínima preocupação com a criação de valores que pudessem estimular o educando a ter respeito pela dignidade da vida.

Diante de tantas controvérsias, surge a necessidade de trabalhar a educação ambiental estimulando o espirito crítico e investigativo do aluno, em que educandos e professores pudessem refletir e contextualizar a questão ambiental e a sustentabilidade, levando em consideração a realidade da sociedade local, e fatores

\footnotetext{
${ }_{4}$ Diretrizes usadas nas demais leis da área ambiental e administrações públicas a nível nacional servindo de padrão as mesmas e, por definição, o primeiro artigo da referida lei preconizou o que se entende por educação ambiental,
} 
como a economia, política e a cultura de cada povo, que deve-se considerar as consequências do tipo de desenvolvimento empregado na natureza e na sociedade (CARVALHO,2006).

A escola, por estar inserida no contexto social, e por ter como principal função educar e formar para a cidadania, detém a importante função de promover uma educação consciente que desperte em seus alunos o senso crítico e ações socioambientais responsáveis (TORALES, 2013). A escola não deve ser responsabilizada como único meio de conscientização ambiental, mas esta deve desenvolver ações educativas bem planejadas, devendo assumir o compromisso potencializador de dimensionar a educação ambiental na formação crítica dos alunos.

É de suma importância que a escola com seu corpo docente, esteja disposta a adotar metodologias e práticas de ensino voltadas para a interdisciplinaridade e multidisciplinaridade, atuando na mediação dos saberes e ações centradas nas práticas de preservação ambiental e conhecimento do meio em que cada aluno vive.

Não cabe mais a escola desenvolver a Educação Ambiental em projetos pontuais ou de forma isolada onde os professores da área de Ciências Naturais ou Biológicas desenvolvem algumas ações principalmente em datas comemorativas como o Dia da Água e Dia do Meio Ambiente. Essa forma de desenvolver a Educação Ambiental não condiz com as teorias e leis que orientam o desenvolvimento da educação ambiental nas unidades escolares para que ocorra a mudança de atitudes e a formação de cidadãos críticos e atuantes sobre as questões ambientais. Tornando-se também um indivíduo multiplicador capaz de sensibilizar a comunidade em que está inserido sobre a importância do equilíbrio e sustentabilidade ambiental.

A escola tem que desenvolver a Educação Ambiental de forma interdisciplinar, isso se tornou um desafio na unidade escolar, já que muitos professores acreditam que falar sobre as questões ambientais deve ser trabalhadas nas aulas de Ciências, Biologia ou Geografia. Com o intuito de quebrar esse paradigma as unidades escolares veem tentando desenvolver projetos com diferentes temáticas e inclusive a questão ambiental que envolva a interdisciplinaridade, multidisciplinariedade ou transdisciplinaridade.

Os educadores necessitam estar capacitados para desenvolver a educação ambiental de forma interdisciplinar desenvolvendo temas que afetem várias 
dimensões como a questão da água, do lixo, saneamento básico, consumo sustentável. Foram implementadas leis para atender essa demanda. As leis que regulamentam e norteiam essas ações são:

A Lei oㅜ 9.394 de 20 de dezembro de 1996, de Diretrizes e bases da Educação Nacional (LDB, que prevê que na formação básica do cidadão seja assegurada a compreensão do ambiente natural e social; que os currículos do Ensino Fundamental e Médio devem abranger o conhecimento do mundo físico e natural; que a Educação Superior deve desenvolver o entendimento do ser humano e do meio em que vive; que a Educação tem como uma de suas finalidades , a preparação para o exercício da cidadania; (BRASIL/CNE,1996, p70).

A Política Nacional de Educação Ambiental estabelece a Educação Ambiental nas escolas como prática integrada continua permanente e transversal a todas as disciplinas como um componente essencial e permanente da educação. A escola tem o desavio de proporcionar alternativas durante o processo ensino aprendizagem com ações que busquem a cidadania capaz de transformar a sociedade. $O$ ambiente escolar é capaz de transformar o indivíduo através da socialização e reflexões dos problemas encontrados na sociedade formando assim uns cidadãos críticos capazes de enfrentar os problemas sociais e que busquem soluções. Vale salientar que:

O aluno precisa ter participação efetiva na construção de tarefas. A realização de gincanas, feiras culturais, seminários e outros trabalhos coletivos têm grande aceitação e merece ser práticas constantes dos professores (MELO, 2004, p.356).

A Educação Ambiental na escola deve ser desenvolvida sobre uma perspectiva de que o ambiente equilibrado e sustentável é fundamental para a existência de vida no planeta. A Educação Ambiental trabalhada de forma interdisciplinar pode contribuir de maneira efetiva para formação cidadã do aluno. Para isso a escola deve desenvolver ações com projeto pedagógicos que contêm atividades importantes para formação do individuo como palestras e debates com temas que envolve o ambiente, oficinas sobre reciclagem e coleta seletiva, teatro, customização de roupas, analise de gráficos e pinturas.

Essas atividades despertam o interesse dos discentes a participarem de forma prazerosa de um projeto de educação ambiental, deixando a prática tradicional de ensino aprendizagem que pouco atraem o interesse dos alunos e se resume a mera transmissão de conhecimentos. 


\title{
Educação Ambiental: Como tema transversal
}

O Tratado de Educação Ambiental para Sociedades Sustentáveis e Responsabilidade Global, elaborado na Conferência das Nações Unidas para o Meio Ambiente e Desenvolvimento (UNICED/92), mais conhecida como "Rio 92", definiu Educação Ambiental como:

\begin{abstract}
A Educação Ambiental para uma sustentabilidade equitativa é um processo de aprendizagem permanente, baseado no respeito a todas as formas de vida. Tal educação afirma valores e ações que contribuem para a transformação humana e social e para a preservação ecológica. Ela estimula a formação de sociedades socialmente justas e ecologicamente equilibradas, que conservam entre si relação de interdependência e diversidade. Isto requer responsabilidade individual e coletiva em nível local, nacional e planetário (UNICED, 1992, [s.p]).
\end{abstract}

As preocupações mundiais e nacionais da Educação Ambiental causaram mudanças na educação brasileira através de leis federais, estaduais e municipais. A Constituição Federal de 1998 atribui ao Poder Público a necessidade de "promover a educação ambiental em todos os níveis de ensino e a conscientização pública para a preservação do meio ambiente" (BRASIL, 1988, [s.p]).

Com a Lei o 9.795, de27 de abril de 1999, que dispõe sobre a educação ambiental e institui a Política Nacional de Educação Ambiental no Brasil. Destaca em seu artigo $3^{\circ}$ que todas as pessoas têm direito à Educação Ambiental e o inciso II do mesmo artigo incumbe às instituições educativas públicas ou privadas promoverem a educação ambiental de maneira integrada aos programas educacionais que desenvolvem (BRASIL, 1999).

Essas tendências foram integradas à proposta dos Parâmetros Curriculares Nacional (PCN, 1998), nos quais o tema meio ambiente aparece como uma proposta transversal, fazendo parte integrante das diversas disciplinas do currículo escolar e devendo ser trabalhada interdisciplinarmente para provocar as mudanças almejadas. A principal função do trabalho com o tema Meio Ambiente é

Contribuir para a formação de cidadãos conscientes, críticos e atuantes na realidade socioambiental de um modo comprometido com a vida, com o bem-estar de cada um e da sociedade, local e global. Para isso é necessário que, mais do que informações e conceitos, a escola se proponha a trabalhar com atitudes, com formação de valores, com o ensino e a aprendizagem de procedimentos. E esse é um grande desafio para a educação. Gestos de solidariedade, hábitos de higiene pessoal e dos diversos ambientes, participação em pequenas negociações são exemplos de aprendizagem que podem ocorrer na escola. (BRASIL/PCN 1999, p.187). 
A inserção do tema 'Meio Ambiente' no currículo escolar vem promover discursões e reflexões acerca da necessidade de preservar e defender o meio ambiente, levando alunos e professores a se tornarem cidadãos comprometidos com a busca de soluções para uma melhor qualidade da vida humana.

De acordo com o PCN na perspectiva escolar, a interdisciplinaridade não tem a pretensão de criar disciplinas ou saberes, mas de utilizar os conhecimentos de várias disciplinas para resolver um problema concreto ou compreender um determinado fenômeno sobre diferentes pontos de vista. Em suma, a interdisciplinaridade tem uma função instrumental. Trata-se de recorrer a um saber diretamente útil e utilizável para responder às questões e aos problemas sociais da contemporaneidade.

A integração dos diferentes conhecimentos pode criar as condições necessárias para uma aprendizagem motivadora, na medida em que ofereça maior liberdade aos professores e alunos para a seleção de conteúdos mais diretamente relacionados aos assuntos ou problemas que dizem respeito à vida da comunidade. Todo conhecimento é socialmente comprometido e não há conhecimento que possa ser aprendido e recriado se não se parte das preocupações que as pessoas detêm.

O distanciamento entre os conteúdos programáticos e a experiência dos alunos certamente responde pelo desinteresse e até mesmo pela deserção que constatamos em nossas escolas.

As questões ambientais exigem do cidadão a conscientização e mudança de postura. Nesse sentido que os novos Parâmetros Curriculares Nacionais propõem o trabalho com o meio ambiente de forma transversal. Os temas transversais são considerados como o eixo norteador, ou seja, está presente em todas as disciplinas, transpondo a concepção, os objetivos, os conteúdos e as orientações didáticas e metodológicas de cada área de conhecimento da Educação Básica.

Pretende-se, assim, fazer com que esses temas integrem as áreas convencionais de forma a estarem presentes em todas elas, relacionando-as às questões da atualidade, pois:

A transversalidade pressupõe um tratamento integrado das áreas e um compromisso das relações interpessoais e sociais escolares com as questões que estão envolvidas nos temas, a fim de que haja uma coerência entre os valores experimentados na vivência que a escola propicia aos alunos e o contato intelectual com tais valores (BRASIL, 1999, p.51). 
Com a utilização de recursos das ciências e da tecnologia, a educação deve desempenhar a função de criar uma consciência e uma melhor compreensão dos problemas que afetam o meio ambiente. A Educação Ambiental surge como conjunto de atos educativos que procuram inserir a variável ambiental em outras disciplinas. A Educação Ambiental não visa apenas aquisição de conhecimento sobre o ambiente, mas a mudança de comportamento, a determinação para a ação e a busca de soluções para os problemas.

A escola desenvolve atividades que buscam o desenvolvimento de habilidades e competências capazes de fazer com que o discente venha ter uma mudança de hábitos através de projetos interdisciplinares, onde as diferentes áreas dos conhecimentos levam esses indivíduos a refletirem sobre suas ações sobre o meio ambiente. Faz-se necessário promover um melhor entendimento e redirecionamento das atividades humanas, devendo-se levar em conta o processo educativo através do qual esse conhecimento esteja sendo construído. Dessa forma, a educação tem um papel fundamental para garantir a sustentabilidade da construção de uma vida equilibrada no Planeta, articulando a humanidade e o ambiente social, natural e físico.

\section{Pedagogia de Projetos na Educação Ambiental}

A ideia de projeto engloba a antecipação de algo desejável que ainda não foi realizado, traz uma ideia de algo que ainda não aconteceu. O processo de projetar implica analisar o presente como fonte de possibilidades futuras. Para compreender a importância da pedagogia de projetos na educação ambiental vê-se necessário entender os conceitos de projetos.

A partir desses conceitos um projeto na área da educação pode ser entendido como forma de planejar e direcionar uma ação pedagógica para que se possa alcançar um objetivo durante o processo de ensino-aprendizagem que busca o desenvolvimento pleno do discente. Projetar significa atirar longe, arremessar, planejar e projeto é concebido como plano, intento, empreendimento, esboço, redação provisória de lei, plano geral de edificação, pois:

A origem da palavra projeto deriva do latim projectus, que significa algo lançado para frente. O projeto não é uma simples representação do futuro, do amanhã, do possível, de uma ideia; é o futuro a fazer, um amanhã a concretizar, um possível a transformar em real, uma ideia a transformar em ato (MACHADO, 2000, p.6) 
Um projeto de verdade é, a princípio, uma irrealidade que vai se tornando real, conforme começa a ganhar corpo a partir da realização de ações e consequentemente, as articulações desta. Considerando esses pensamentos sobre o conceito de projeto percebe-se que trabalhar com projetos nas escolas é um caminho inovador para que o processo de ensino-aprendizagem ocorra de forma dinâmica, construtiva possibilitando uma melhor aprendizagem dos alunos. Porém é necessário que o professor conheça os objetivos a serem alcançados.

Em um projeto os alunos desenvolvem atividades de forma intensa, fator que contribui para sua aprendizagem, ou seja, estão aprendendo a serem indivíduos autônomos que podem ser mediado pelo professor e se tornarem construtor do seu próprio conhecimento através de pesquisas e experiências que são vivenciadas durante o desenvolvimento do projeto. Sobre a aprendizagem significativa pode-se afirmar que:

O modelo de aprendizagem significativa dá ênfase (frente a aprendizagem descoberta) ao caráter verbal que deve estar presente nas situações de ensino. Isso ocorre porque o aluno é induzido a ir em busca do conhecimento através de conteúdos que são vistos no seu cotidiano, seja este do campo social ou cultural (HERNÁNDEZ ; VENTURA,2002, p.32).

Trabalhar com projeto faz com que ocorra uma globalização das disciplinas, ou seja, a interdisciplinaridade se entende fundamentalmente como a tentativa voluntária de integração de diferentes ciências com objetivos em comum. Sendo assim, a abordagem irá contribuir para aprendizagem do aluno fazendo com seja mais crítico e reflexivo. Fortalece essa linha de pensamento considerando que:

Os projetos devem ter uma dimensão interdisciplinar. Um projeto com dimensão interdisciplinar faz com que o aluno tenha diferentes visões sobre determinado conteúdo possibilitando um aprendizado significativo. Aprendizado esse que possibilita a interagir e agir de forma crítica sobre diferentes situações sociais e ambientais (VENTURA, 2002, p.5).

Através do projeto interdisciplinar possibilita ao aluno ter um desenvolvimento e aprendizado geral nas diversas disciplinas. A interdisciplinaridade possibilitará ao indivíduo além do desenvolvimento intelecto, fazer com que ocorra a produção do conhecimento. Isso porque através do projeto possibilitará ao indivíduo além do desenvolvimento intelecto, irá fazer com que ocorra a produção do conhecimento. Nessa linha de pensamento "a interpretação da noção de estrutura não se refere a 
unicamente às disciplinas, e sim à maneira de promover um pensamento reflexivo nos alunos" (HERNANDES e VENTURA, 2002, p.39).

De acordo com esse contexto trabalhar com projetos possibilita criar e recriar através de um tema proposto uma perspectiva do conhecimento globalizado através de atividades que podem ser desenvolvidas ligadas não apenas a um conhecimento, mas sim a todas as áreas do saber. O indivíduo pode se desenvolver por completo, tendo diferentes visões da área do conhecimento possibilitando a formação de indivíduos capaz de interagir, interpretar e agir nas diferentes situações que vivenciam na sociedade em que estão inseridos.

O trabalho com projetos requer mudanças na concepção do processo ensinoaprendizagem, levando assim, a uma mudança na forma como o professor atua. $\mathrm{Na}$ educação tradicional o professor era o detentor do conhecimento e atuava decidindo e definindo o conteúdo e as tarefas a serem desenvolvidas não levando em consideração o conhecimento prévio do aluno, era apenas um transmissor de conhecimento.

$\mathrm{Na}$ pedagogia de projeto o professor deixa de ser o centro das atenções e o discente passa a ter um protagonismo maior, pois a atividade do sujeito aprendiz é determinante na construção do saber e esse sujeito nunca está sozinho ou isolado, age em constante interação com os pares e meios ao seu redor. Na pedagogia de projeto o aluno aprende em todas as etapas, pois aprende no processo de aprendizagem, de levantar dúvidas, de pesquisar de criar relações que incentivam novas buscas, descobertas, compreensão e reconstruções de conhecimentos.

Ao trabalhar com projeto se faz uma globalização das disciplinas "a interdisciplinaridade se entende fundamentalmente como a tentativa voluntária de integração de diferentes ciências Brasília: SEE/ CNE com objetivo comum" (Ibid., p 53). Essa abordagem contribui para que o aluno se torna um indivíduo mais reflexivo.

Ao desenvolver um projeto de educação ambiental permanente a escola pode proporcionar ações sobre a questão ambiental e reavaliar essas ações proposta para o processo ensino aprendizagem para seja de forma contextualizada atingindo a assim seus objetivos na formação do cidadão, pois "a interpretação da noção de estrutura não se refere unicamente ás disciplinas, e sim à maneira de promover um pensamento reflexivo nos alunos" (Ibid., p. 39). 
De acordo com esse contexto de valorização, desenvolver um projeto permite criar e recriar ações diante de determinado tema proposto durante o processo ensino aprendizagem em uma perspectiva interdisciplinar. Isso possibilita desenvolver atividades ligadas ao todo saber.

\section{A Importância do Projeto Pedagógico Interdisciplinar Para o Desenvolvimento da Educação Ambiental}

A globalização proporcionou ao mundo contemporâneo uma nova forma de agir e pensar, fazendo com que fossem revistas as teorias pedagógicas utilizadas pelas escolas. Em um mundo globalizado é necessário que o conhecimento desenvolva habilidades de forma integrada. A escola tradicional ao longo de décadas trabalhou os conteúdos de forma isolada fazendo com que certas habilidades não fossem desenvolvidas de forma ampla e completa não satisfazendo assim o desenvolvimento do aprendizado que o mundo contemporâneo requer hoje. A interdisciplinaridade proporciona um aprendizado significativo para um mundo globalizado.

Os conteúdos escolares estão organizados por áreas do conhecimento de forma bem sedimentadas, possuindo contornos definidos e específico de cada uma delas. $O$ ensino e a produção do conhecimento estão, portanto, baseado numa forma fragmentada e estanque. Hoje vê-se a necessidade de modificar esta forma arraigada de desenvolver a educação, tornando-a mais contextualizada, mais próxima da realidade do aluno, sem criar novas disciplinas. A inclusão dos temas transversais nos currículos escolares busca fazer esta integração, pois:

A preocupação em recuperar este referencial unificador para nossa docência aconselha que tenhamos clareza das diferenças que há entre conteúdos mais fechados e mais abertos. [...] O ensino nos treina, nos torna capazes de aprender certas capacidades que podemos chamar de 'fechadas': algumas estritamente funcionais como andar, vestir-se, outras mais sofisticadas como ler, escrever e contar. São habilidades extremamente úteis e imprescindíveis para a vida diária, para o trabalho, e para outros aprendizados. [...] Essas habilidades fechadas se esgotam uma vez aprendidas. [...] Há capacidades 'abertas': o convívio social, a ética, a cultura, as identidades, os valores da cidade, do trabalho, da cidadania, relações sociais de produção, os direitos, o caráter, as condutas, a integridade moral, a consciência política, os papéis sociais, os conceitos e preconceitos, o destino humano, as relações entre os seres humanos, entre os iguais e os diversos, o universo simbólico, a interação simbólica com os outros, nossa condição espacial e temporal, nossa memória coletiva e herança cultural, o cultivo do raciocínio, o aprender a aprender, aprender a 
sentir, a ser... Esses conteúdos [...] nunca foram fechados em grade, nem se prestam a ser disciplinas em disciplinas (ARROIO, 2000, p.70).

$\mathrm{Na}$ literatura especializada não há uma definição unívoca do conceito de interdisciplinaridade, ela pode ser considerada como a cooperação de várias disciplinas no exame de um mesmo objeto ou como intercâmbio mútuo e relação mútua entre várias disciplinas tendo como resultado um enriquecimento recíproco. $\mathrm{A}$ interdisciplinaridade é a interação interior e conceitual que irrompe a composição de cada disciplina para estabelecer uma axiomática nova e com um a todas elas, com a finalidade de propor um novo ponto de vista do saber.

A interdisciplinaridade como a integração interna e conceptual que rompe a estrutura de cada disciplina para construir uma nova e comum a todas elas, com o fim de dar uma visão unitária de um sector do saber. A pluridisciplinaridade é a associação ou integração mínima de duas ou mais disciplinas, não exigindo alterações na forma e na organização do ensino (PALMATE, 1979).

Do ponto de vista da diretriz de política governamental, o Ministério da Educação por meio dos Parâmetros Curriculares Nacionais procura orientar quanto a atitudes e ações interdisciplinares, pois:

A interdisciplinaridade é entendida no $\mathrm{PCN}$ do ensino médio como função instrumental, a de utilizar os conhecimentos de várias disciplinas para resolver um problema concreto ou compreender um determinado fenômeno sob diferentes pontos de vista a partir de uma abordagem relacional (KAVESKI, 2005, p.128).

A interdisciplinaridade caracteriza-se pela intensidade das trocas entre os especialistas e pelo grau de integração real das disciplinas no interior de um mesmo projeto. A interdisciplinaridade visa à recuperação da unidade humana pela passagem de uma subjetividade para uma intersubjetividade, e assim sendo, recupera a ideia primeira de cultura (formação do homem total), o papel da escola (a formação do homem inserido em sua realidade) e o papel do homem (agente das mudanças do mundo).

Tendo como base essa definição a interdisciplinaridade proporciona o rompimento das estruturas de todas as disciplinas para alcançar uma axiomática comum através da flutuação nas diferentes áreas do conhecimento com a cooperação, intercambio e integração recíproca.

A interdisciplinaridade promove um intercâmbio entre as disciplinas nas suas mais diversas áreas, já que, proporciona a aquisição de conhecimento através de 
temáticas e conteúdos diversificados possibilitando assim uma aprendizagem dinâmica e ampla, uma vez que:

O pensar interdisciplinar provem da premissa de que nenhuma forma de conhecimento é por si mesmo racional, pois busca o diálogo com outras formas de conhecimento, deixando-se interpenetrar por elas. Dessa forma aceita o conhecimento do senso comum como valido, já que, através das experiências diárias damos sentido a nossas vidas (FAZENDA, 2002, [s.p]).

De modo, geral a interdisciplinaridade, faz com que os professores integrem os conteúdos da história com os da geografia, os de química com os de biologia, ou mais do que isso, em interagir de forma entusiástica no início do projeto, os conteúdos de todas as disciplinas e atividades que compõem a grade curricular, considerando, no entanto, que nessa perspectiva não conseguem ter um avanço considerável. Não se pode deixar de destacar que:

\begin{abstract}
A interdisciplinaridade surge na metade do século passado, em resposta a uma necessidade verificada principalmente nos campos das Ciências Humanas e da Educação: superar a fragmentação e o caráter de especialização do conhecimento, causados por uma epistemologia de tendência positivista em cujas raízes o empirismo, o naturalismo e o mecanismo cientifico do início da modernidade (GADOTTI, 1993,[s.p]).
\end{abstract}

As teorias construtivistas afirmam que o aluno deve ser desenvolvido por completo, em todas as suas habilidades e ao mesmo tempo. Dessa forma a base curricular deve ser integrada proporcionando ao aluno novas formas de aprendizagem. Dessa forma o currículo das diferentes modalidades de ensino deve fazer com que o ensino ocorra de tal forma que integre todas as áreas do conhecimento: exata, humanas e linguagens. Hoje se fala que a escola tem a função de formar o cidadão integral, pois:

Os PCNs têm objetivos que demonstram ter amplitude no desenvolvimento do aluno [...] os objetivos se definem nos PCNs em termos de capacidades de ordem cognitiva, física, afetiva, de relação interpessoal e inserção social, ética e estética, apontando desta forma uma formação ampla (BRASIL, 2001, p. 52).

Os PCNs tratam da capacidade cognitiva como uma capacidade de resolver problemas em diferentes situações de vida, aplicando para isso as aquisições da linguagem, matemática, representações espaciais, temporais, gráficas, o corpo e as expressões de emoção.

A ideia do sujeito integral nos leva a conceder um conjunto de área (cognitiva, motora, afetiva e social) que proporciona ao discente uma aprendizagem 
experenciada, com interação ao meio, partindo do simples para o complexo, provocando desafios, visando a resolução de problemas e autonomia no direito de exercer a cidadania na sociedade em que vive.

\section{Considerações}

A escola é um espaço multicultural por isso é fundamental que as ações pedagógicas façam algum sentido para os alunos, professores e comunidade escolar. Esse é um ponto importante a ser considerado no momento da elaboração do Projeto Político Pedagógico (PPP) que podem ser desenvolvido de forma multidisciplinar, interdisciplinaridade ou transdisciplinar. Ao inserir a Educação Ambiental no PPP da escola esta legitimando que ação da Educação Ambiental ocorrerá durante o ano letivo possibilitando assim a comunidade escolar desenvolver os projetos pedagógicos que visam a sensibilização e o desenvolvimento da consciência ambiental da comunidade escolar. Mediante tal abordagem a Educação Ambiental deve estar inserida no PPP para que suas ações sejam concretizadas e contribua para formação cidadão critico e atuante na sociedade,

No projeto interdisciplinar sobre Educação Ambiental as disciplinas dialogam entre si e se complementam dando origem a novos conceitos. Consiste na integração de várias e diferentes áreas do conhecimento num trabalho de troca e cooperação. E para que haja uma participação prazerosa o professor deve trabalhar a Educação Ambiental com a realidade da sua clientela, buscando envolve-los em atividades que levem a reflexão critica sobre suas atitudes em relação ao ambiente para despertar neles a curiosidade e também fazer com que busquem alternativas para cuidar melhor do meio em que vive.

O projeto interdisciplinar supera a visão cartesiana de educação, onde os conteúdos estão isolados nas disciplinas, tornando a educação algo realmente significativo para os alunos e comunidade escolar. No projeto interdisciplinar de Educação Ambiental ocorrem posturas e ações onde os professores tratam os temas relacionados às questões ambientais não somente em suas disciplinas isoladamente, buscam estabelecer um diálogo. Para tanto os professores precisam estar engajados e ter um conhecimento básico do conteúdo a ser trabalhado e que façam referências aos outros conteúdos

Vale destacar que no projeto interdisciplinar sobre Educação Ambiental a escola deve promover ações para que a comunidade possa se envolver com o 
processo educativo dos alunos uma vez que a instituição tem como objetivo preparar o aluno para viver em sociedade. A participação da comunidade tem grande importância, uma vez que a escola reflete várias dimensões que ocorre na sociedade, logo não há como não existir uma relação entre as instituições educacionais e a comunidade onde as mesmas estão inseridas. A escola para conduzir as práticas pedagógicas necessita do apoio e participação de todos que formam um meio social específico.

\section{Referências:}

ARROYO, M. G. Ofício de Mestre: imagens e auto-imagens. Petrópolis,RJ: Vozes, 2000.

BRASIL. A Constituição Federal de 1998. Brasília: MEC, 1988

BRASIL. Lei de Diretrizes e Bases da Educação Nacional no 9394/96. Brasília, 1996.

BRASIL, Ministério da Educação e do Desporto, Lei no. 9.795 de 27 de abril de 1999. Dispõe sobre a educação ambiental, institui a Política Nacional de Educação Ambiental e dá outras providências. Brasília: Diário Oficial da República Federativa do Brasil, 1999.

BRASIL. Parâmetros curriculares nacionais: ensino médio. Secretaria de Educação Média e Tecnológica. Brasília: MEC/SEF, 1999.

BRASIL. Ministério da Educação. Secretaria de Educação Fundamental. Parâmetros curriculares nacionais: ensino fundamental. Introdução. Brasília: SEE/ CNE, 2001.

BRASIL. Diretrizes Curriculares Nacionais para a Educação Ambiental. Resolução CNE/CP 2/2012.

CARVALHO, I. C. M. Educação ambiental: a formação do sujeito ecológico. 2. ed. São Paulo: CORTEZ, 2006.

FAZENDA, I. C. A. Integração e interdisciplinaridade no ensino brasileiro: efetividade ou ideologias. 5.ed. São Paulo: Edições Loyola, 2002.

GADOTTI, M. A organização do trabalho na escola: alguns pressupostos. São Paulo: Ática, 1993.

HERNÁNDEZ e VENTURA, D. Monografia jurídica. Porto Alegre: Livraria do Advogado, 2002.

KAVESKI, F. C. G. Concepções acerca da interdisciplinaridade e transdisciplinaridade: um estudo de caso. Vitória/Vila Velha, [s.I], 2005.

MACHADO, N. J. Educação: projetos e valores. São Paulo: Escrituras Editora, 2000.

MELO M. G. A. Ensino de Física nas Escolas de Nível Médio de Belém-Pará. In: Congresso Internacional de Educação: Os Desafios no Processo de Ensino aprendizagem. João Pessoa: Anais..São Luiz: Ed. Universitária, 2004

UNICED Declaração do Rio de Janeiro Sobre Meio Ambiente e Desenvolvimento. Rio de Janeiro: Relatório, 1992.

PALMADE, G. Interdisciplinaridade e ideologias. Madrid: Narcea.[s.I] 1979 REBOUÇAS, J. P. A educação ambiental entre reprodução e emancipação: experiências em escolas públicas de Mossoró/RN. Dissertação (Mestrado). João Pessoa: UFP, 2012. 
TORALES, M.T. A Inserção da educação ambiental nos currículos escolares e o papel dos professores: da ação escolar a ação educativo-comunitária como compromisso político pedagógico. Rio Grande do Sul Revista do PPGEA/ FURG, 2013.

VENTURA, P. C. S. Por uma Pedagogia de projetos: uma síntese introdutória. Educação \& Tecnologia, CEFET-MG. Belo Horizonte, V.7, N.1 - Jan. a Jun./2002. 